\title{
Prediction factors for failure to seek treatment following traumatic dental injuries to primary teeth
}

Ramon Targino FIRMINO(a) Maria Betânia Lins Dantas SIQUEIRA ${ }^{(a)}$

Raquel Gonçalves VIEIRAANDRADE(b)

Genara Brum GOMES(c)

Carolina Castro MARTINS(c)

Saul Martins PAIVA(c)

Ana Flávia GRANVILLE-GARCIA(a)

(a) Department of Pediatrics, School of Dentistry, Universidade Estadual da Paraíba - UEPB, Campina Grande, PB, Brazil.

(b)Department of Pediatric Dentistry, School of Dentistry, Universidade Federal dos Vales do Jequitinhonha e Mucuri - UFVJM, Diamantina, MG, Brazil.

(c)Department of Pediatric Dentistry and Orthodontics, School of Dentistry, Universidade Federal de Minas Gerais UFMG, Belo Horizonte, MG, Brazil.

Declaration of Interests: The authors certify that they have no commercial or associative interest that represents a conflict of interest in connection with the manuscript.

Corresponding Author: Ana Flávia Granville-Garcia

E-mail: anaflaviagg@hotmail.com

DOI: 10.1590/1807-3107BOR-2014.vol28.0005 Epub Jun 02, 2014

Submitted: Jun 11, 2013

Accepted for publication: Nov 26, 2013

Last revision: Jan 13, 2013

\begin{abstract}
The objective of this study was to evaluate prediction factors for failure to seek treatment following a traumatic dental injury (TDI) to primary teeth among preschool children in the city of Campina Grande, Brazil. A cross-sectional study was carried out involving 277 children 3 to 5 years of age, with TDI, enrolled in public and private preschools. Parents filled out a form addressing demographic data and whether or not they had sought treatment. Clinical examinations were performed by three dentists who had undergone a calibration exercise (Kappa: 0.85 to 0.90) for the evaluation of TDI. Bivariate and multivariate Poisson regression models were constructed $(\alpha=5 \%)$. Enamel fracture was the most prevalent type of TDI $(48.7 \%)$ and the upper central incisors were the most affected teeth (88.4\%). The frequency of seeking dental treatment was low $(9.7 \%)$. The following variables were associated with failure to seek treatment following TDI: a household income greater than one minimum wage ( $\mathrm{PR}=1.170 ; 95 \% \mathrm{CI} 1.018-1.341)$, parents/caregivers' perception of a child's oral health as poor $(\mathrm{PR}=1.100$; 95\%CI 1.026-1.176), and the non-perception of TDI by parents/caregivers $(\mathrm{PR}=1.250 ; 95 \% \mathrm{CI} 1.142-1.360)$. In the present study, the frequency of seeking treatment following TDI was low, and parents/caregivers with a higher income, a poor perception of their child's oral health and a lack of awareness regarding the trauma were more likely to fail to seek treatment following TDI to primary teeth.
\end{abstract}

Keywords: Tooth Injuries; Risk Factors; Dental Care.

\section{Introduction}

Traumatic dental injury (TDI) in preschool children constitutes a public health problem due to its high prevalence, its impact on quality of life, treatment costs and eventual long-term consequences to oral health., ${ }^{1,2,3}$ Epidemiological studies report that approximately one third of preschoolers suffer TDI when they learn to crawl, stand, walk and run. Indeed, imprecise movements in this period make children more prone to experiencing falls from their own height, which can lead to TDI. ${ }^{2,3,5,6}$

TDI is usually sudden, circumstantial and unexpected. It affects mineralized tissues (tooth and bone), and damages dental pulp and periodontal tissues by causing rupture, hyperemia or hemorrhage. Dental trauma causes pain, obliterates the pulp cavity and leads to tooth mobility, sensitivity to percussion, crown discoloration, pulp 
necrosis, pathological root resorption and hypoplasia, or complete malformation of permanent teeth. $3,7,8,9$ While TDI often requires urgent care, parents/caregivers are generally ill-informed regarding the risks and consequences of dental trauma and what can be done to avoid it. ${ }^{8,10}$ Moreover, the timeliness and appropriateness of seeking dental care depend on the parents/caregivers' awareness of the child's oral condition. ${ }^{11,12}$

Overall, the frequency of seeking dental treatment following trauma to primary teeth is low. ${ }^{13,14}$ Only one national study addressed socioeconomic factors and the perceptions of parents/caregivers regarding the oral health status of their children, and found that such factors were predictive of seeking treatment following TDI. ${ }^{15}$ However, the study cited did not involve a representative sample. Thus, investigations are needed to address prediction factors for seeking treatment in such cases, thus contributing to public health policies that emphasize the need for post-trauma treatment to diminish eventual consequences.

The aim of the present study was to evaluate prediction factors for failure to seek treatment following a traumatic dental injury (TDI) in primary teeth among preschool children.

\section{Methodology}

\section{Sample Characteristics}

A cross-sectional, school-based study was carried out involving children three to five years of age, enrolled at public and private preschools in Campina Grande, Brazil. Campina Grande (population: 386,000 inhabitants) is an industrialized city in northeastern Brazil, divided into six health districts. The city has cultural and socioeconomic disparities, with a mean monthly income of US $\$ 110$ per capita and a Human Development Index of $0.72{ }^{16}$

A two-phase random sampling strategy was employed to ensure representativeness. Preschools were randomly selected by lot from each health district, in the first phase, and children were randomly selected by lot from each preschool, in the second phase. Eighteen of the 127 public preschools and 15 of the 122 private preschools were selected. The sample size was calculated based on a $4 \%$ margin of error, a 95\% confidence level and a 50.0\% prevalence rate of TDI. A correction factor of 1.2 was applied to increase the precision, leading to a minimum sample size of 720 schoolchildren. A further $20 \%$ was added to compensate for possible losses, giving a total sample of 864 schoolchildren. Data collection was carried out between February and May 2012. In the present study, only children with a normative diagnosis of TDI $(34 \% ; n=277)$ were included.

This study received approval from the Human Research Ethics Committee of the Universidade Estadual da Paraíba (Brazil) under process no. 00460133000-11, in compliance with Resolution 196/96 of the Conselho Nacional de Saúde (CNS - Brazilian National Health Council). All parents/caregivers signed a statement of informed consent.

\section{Eligibility criteria}

The inclusion criteria were three to five years of age, enrollment in preschool, absence of systemic disease according parents/caregivers' information, and the return of completed questionnaires. The exclusion criteria were having four missing maxillary incisors due to caries or physiological exfoliation, which could compromise the clinical diagnosis of TDI.

\section{Training and calibration exercise}

The calibration exercise consisted of two steps (theoretical and clinical). The theoretical step involved a discussion of the criteria for the diagnosis of TDI and an analysis of photographs. The clinical step was performed at a randomly selected preschool that was not part of the main sample. Three dentists examined 50 previously selected children between three to five years of age. Interexaminer agreement was tested by comparing each examiner with the gold standard. A seven-day interval was respected between clinical examinations in determining intraexaminer agreement. Data analysis involved Cohen's Kappa coefficient on a tooth-by-tooth basis. Kappa values ranged from 0.85 to 0.90 for intraexaminer and interexaminer agreement.

\section{Pilot study}

A pilot study was performed to test the methodology and comprehension of the questionnaires. The 
children in the pilot study $(n=40)$ were not included in the main sample. Since there were no misunderstandings regarding the questionnaire or the methodology, no changes had to be made to the data collection process.

\section{Non-clinical data collection}

The parents/caregivers of children with a normative diagnosis of TDI were asked to answer a questionnaire containing two sections: (i) sociodemographic data - information on parent/caregiver's age and years of schooling, number of residents in the home, monthly household income (categorized, based on the minimum wage [US\$312.50/month]), child's birth order and type of school; and (ii) dental trauma as reported by the parent/caregiver - history of TDI, and the decision to seek dental care following the occurrence of TDI.

\section{Clinical data collection}

Oral examinations were performed with a portable lamp attached to the examiner's head (Petzl Zoom headlamp, Petzl America, Clearfield, USA). The children were seated in school chairs in front of the examiner. The dentists used individual cross-infection protection equipment, as well as packaged, sterilized mouth mirrors (PRISMA ${ }^{\circledR}$, São Paulo, Brazil), Williams' probes (WHO-621, Trinity ${ }^{\circledR}$, Campo Mourão, Brazil) and dental gauze. The classification proposed by Andreasen et al. ${ }^{17}$ was used for the clinical diagnosis of TDI: enamel fracture, enamel + dentin fracture, complicated crown fracture, extrusive luxation, lateral luxation, intrusive luxation and avulsion. A visual assessment of tooth discoloration was also performed.

\section{Statistical Analysis}

Frequency distributions of the data were determined. The independent variables were sociodemographic factors, parents/caregivers' perceptions of the child's oral health status, presence of trauma according to the parents/caregivers, type of trauma and number of teeth with trauma. Failure to seek treatment following TDI was the dependent variable. Bivariate Poisson regression analysis with robust variance was employed to determine associations between the independent and dependent variables $(p<0.05)$. Forward stepwise multivariate Poisson regression models were constructed for variables with a $p$-value $<0.20$ in the bivariate analysis. Statistical analysis was performed using the Statistical Package for Social Sciences (SPSS for Windows, version 18.0, SPSS Inc., Chicago, USA).

\section{Results}

A total of 277 pairs of parents/children participated in the present study (response rate of 100\%). Table 1 displays the characterization of the sample.

One hundred and seventy-three children exhibited only one tooth with TDI. The upper central incisors were the most affected (88.4\%), and enamel fracture was the most common type of TDI (48.7\%). One hundred and twenty-one parents perceived the occurrence of TDI and two hundred and fifty failed to seek treatment following TDI. (Table 2)

Table 1. Frequency distribution of preschool children according to gender, age, type of school, mother's schooling and monthly family income.

\begin{tabular}{lcc}
\hline \multirow{2}{*}{ Variable } & \multicolumn{2}{c}{ Frequency } \\
\cline { 2 - 3 } & $\mathrm{N}$ & $\%$ \\
\hline Gender & 153 & 55.2 \\
Male & 124 & 44.8 \\
Female & 277 & 100.0 \\
Total & & \\
Age & 84 & 30.3 \\
3 years & 110 & 39.7 \\
4 years & 83 & 30.0 \\
5 years & 277 & 100.0 \\
Total & & \\
Type of school & 142 & 51.3 \\
Public & 135 & 48.7 \\
Private & 277 & 100.0 \\
Total & & \\
Mother's schooling & 123 & 44.6 \\
Up to 8 years of schooling & 153 & 55.4 \\
Over 8 years of schooling & $276^{*}$ & 100.0 \\
Total & & \\
Household income & 48 & 18.0 \\
$\leq$ One minimum wage & 219 & 82.0 \\
Total & & 100.0 \\
\hline
\end{tabular}

*1 interviewee did not provide this information

**10 interviewees did not provide this information 
Table 2. Frequency distribution of preschool children according to type of trauma, number of teeth involved, teeth affected, parents/guardians' perception of trauma and failure to seek treatment following TDI.

\begin{tabular}{lcc}
\hline \multirow{2}{*}{ Variable } & \multicolumn{2}{c}{ Frequency } \\
& $N$ & $\%$ \\
\hline Type of trauma & 90 & 32.5 \\
Discoloration & 135 & 48.7 \\
Enamel fracture & 39 & 14.1 \\
Enamel and dentin fracture & 9 & 3.2 \\
Luxation & 4 & 1.4 \\
Avulsion & & \\
Number of teeth involved & 173 & 62.5 \\
1 & 104 & 37.5 \\
2 or more & & \\
Teeth affected & 329 & 88.4 \\
Upper central incisors & 33 & 8.9 \\
Upper lateral incisors & 10 & 2.7 \\
Lower incisors & & \\
Parents/caregivers' perception of & & \\
trauma & & \\
Present & 121 & 43.7 \\
Absent & 156 & 57.3 \\
Failure to seek treatment following & & \\
TDI & & \\
No & 27 & \\
Yes & & \\
\hline
\end{tabular}

Table 3 shows the predisposing factors regarding failure to seek treatment following TDI. The following variables remained in the final multivariate Poisson model: monthly income > one minimum wage (PR = 1.170; 95\%CI 1.018-1.341), parent/caregivers' perception of child's oral health as poor $(\mathrm{PR}=1.100$; 95\%CI 1.026-1.176) and non-perception of TDI by parents/caregivers ( $\mathrm{PR}=1.250 ; 95 \% \mathrm{CI} 1.142-1.360)$.

\section{Discussion}

As a public health problem, TDI requires the implementation of educational and preventive programs based on the understanding of the scope of the problem, according to respective populations. In the present study, enamel fracture was the most prevalent type of TDI, followed by discoloration; upper central incisors were the most affected teeth, and the majority of children had only one tooth with trauma. These findings are in agreement with data reported in previous studies. ${ }^{2,5,13,15,18}$ It is important to bear in mind that the prevalence of dental trauma is often underreported, due to memory bias resulting from the healing of symptoms, or because mothers or children tend to forget such incidents. ${ }^{19}$

A favorable prognosis and greater chance of treatment success following dental trauma are directly related to the time elapsed between injury and dental care. ${ }^{20}$ The frequency of seeking treatment was low in the present study, which is in agreement with findings reported in previous studies. ${ }^{13}$ To the best of our knowledge, there is only one investigation that has explored this issue in an in-depth fashion - a non-representative Brazilian study in which predisposing factors for seeking treatment were found only in children whose parents/caregivers perceived the TDI. ${ }^{15}$ In the present study, children with a normative diagnosis of TDI were selected from a representative study, and the influence of parents/caregivers' perceptions of TDI on the decision to seek dental treatment was investigated.

Three variables were predictors of failure to seek treatment following TDI: income, parents/caregivers' perception regarding their child's oral health status and parents/caregivers' perception of TDI. Curiously, parents/caregivers who earned more than the minimum wage were less likely to seek treatment following trauma. Although the parents' occupations were not investigated in the present study, the current trend is for both parents to work, and it is possible that those who spend most of their day working outside the home are often unaware of the occurrence of TDI. Indeed, the percentage of parents who did not perceive the trauma was high, which is in agreement with findings described in previous studies. ${ }^{913,15}$ Thus, leaving a child with caregivers at home or in daycare centers may play an important role in failing to seek treatment. On the other hand, the infrequent perceptions of TDI may be related to memory bias regarding the occurrence of the event. Toddlers with a dental condition do not manifest pain or discomfort, in part, because they do not fully grasp the concept of a toothache. They do, however, exhibit the behavioral effects of pain through changes in eating and sleeping habits. It is more difficult for parents to recognize dental trauma in toddlers. ${ }^{9}$ Moreover, trauma of little 
Table 3. Frequency and Poisson regression analysis according to independent variables and failure to seek treatment following TDI in preschool children.

\begin{tabular}{|c|c|c|c|c|c|c|}
\hline \multirow{3}{*}{ Variable } & \multicolumn{2}{|c|}{ Failure to seek treatment TDI } & \multirow{2}{*}{\multicolumn{2}{|c|}{$\begin{array}{c}\text { Bivariate } \\
\text { Unadjusted PR }\end{array}$}} & \multirow{2}{*}{\multicolumn{2}{|c|}{$\begin{array}{l}\text { Multivariate } \\
\text { Adjusted PR }\end{array}$}} \\
\hline & \multirow{2}{*}{$\begin{array}{l}\text { No } \\
n(\%)\end{array}$} & \multirow{2}{*}{$\begin{array}{l}\text { Yes } \\
n(\%)\end{array}$} & & & & \\
\hline & & & $p$-value ${ }^{(1)}$ & $(95 \% \mathrm{Cl})$ & $p$-value ${ }^{(1)}$ & $(95 \% \mathrm{Cl})$ \\
\hline \multicolumn{7}{|l|}{ Gender } \\
\hline Male & $15(9.8)$ & 138(90.2) & \multirow{2}{*}{0.972} & 1.00 & - & - \\
\hline Female & $12(9.7)$ & $112(90.3)$ & & $1.001(0.926-1.082)$ & - & - \\
\hline \multicolumn{7}{|l|}{ Child's age } \\
\hline 5 years & $9(10.8)$ & $74(89.2)$ & \multirow{2}{*}{0.832} & 1.00 & \multirow[t]{3}{*}{-} & - \\
\hline 4 years & 13(1 1.8) & $97(88.2)$ & & $0.989(0.894-1.095)$ & & - \\
\hline 3 years & $5(6,0)$ & $79(94.0)$ & 0.257 & $1.055(0.962-1.157)$ & & \\
\hline \multicolumn{7}{|l|}{ Type of school } \\
\hline Public & 13(9.2) & $129(90.8)$ & \multirow{2}{*}{0.734} & 1.00 & - & - \\
\hline Private & $14(10.4)$ & $121(89.6)$ & & $0.987(0.913-1.066)$ & - & - \\
\hline \multicolumn{7}{|l|}{ Mother's schooling } \\
\hline$>8$ years & $17(11.1)$ & $136(88.9)$ & \multirow{2}{*}{0.400} & 1.00 & - & - \\
\hline$\leq 8$ years & $10(8.1)$ & $113(91.9)$ & & $1.034(0.957-1.116)$ & - & - \\
\hline \multicolumn{7}{|l|}{ Caregiver's age } \\
\hline$\leq 30$ years & $9(6.8)$ & 123(93.2) & \multirow{2}{*}{0.148} & 1.00 & - & - \\
\hline$>30$ years & $17(11.9)$ & $126(88.1)$ & & $1.058(0.980-1.141)$ & - & - \\
\hline \multicolumn{7}{|l|}{$\begin{array}{l}\text { Number of residents in the } \\
\text { home }\end{array}$} \\
\hline$\geq 6$ & $4(10.3)$ & $35(89.7)$ & \multirow{2}{*}{0.889} & 1.00 & - & - \\
\hline$<6$ & $22(9.5)$ & $209(90.5)$ & & $1.008(0.889-1.130)$ & - & - \\
\hline \multicolumn{7}{|l|}{ Household income } \\
\hline$\leq$ One minimum wage & $11(22.9)$ & $37(77.1)$ & \multirow{2}{*}{0.016} & 1.0 & 0.026 & 1 \\
\hline$>$ One minimum wage & $14(6.4)$ & $205(93.6)$ & & $1.214(1.037-1.422)$ & & $1.170(1.018-1.341)$ \\
\hline \multicolumn{7}{|l|}{$\begin{array}{l}\text { Did the child suffer trauma } \\
\text { to primary teeth? }\end{array}$} \\
\hline Yes & $27(22.3)$ & $94(77.7)$ & \multirow{2}{*}{$<0.001$} & 1 & 0.000 & 1 \\
\hline No & $0(0)$ & 156(100) & & $1.287(1.170-1.416)$ & & $1.250(1.142-1.360)$ \\
\hline \multicolumn{7}{|l|}{ Type of trauma } \\
\hline Avulsion and luxation & $4(30.8)$ & $9(69.2)$ & & 1 & & \\
\hline $\begin{array}{l}\text { Enamel and enamel }+ \\
\text { dentin fracture }\end{array}$ & $10(5.7)$ & $164(94.3)$ & 0.097 & $1.361(0.946-1.960)$ & - & - \\
\hline Discoloration & $13(14.4)$ & $77(85.6)$ & 0.265 & $1.236(0.852-1.793)$ & - & - \\
\hline \multicolumn{7}{|l|}{$\begin{array}{l}\text { Number of teeth with } \\
\text { trauma }\end{array}$} \\
\hline 2 or more & $13(12.5)$ & $91(87.5)$ & \multirow{2}{*}{0.257} & 1 & - & - \\
\hline 1 & $14(8.1)$ & 159(91.9) & & $1.050(0.965-1.144)$ & - & - \\
\hline \multicolumn{7}{|l|}{$\begin{array}{l}\text { Parents/guardians' } \\
\text { perception of child's oral } \\
\text { health }\end{array}$} \\
\hline Good & $27(10.3)$ & $236(89.7)$ & $<0.001$ & 1 & 0.007 & 1 \\
\hline Poor & $0(0)$ & 13(100) & & $1.114(1.070-1.161)$ & & $1.100(1.026-1.176)$ \\
\hline
\end{tabular}


magnitude, such as enamel fracture, may not cause discomfort, and may thus hinder detection by laypersons. Authors have reported a trend toward seeking dental care following trauma when symptoms are evident. ${ }^{21}$

The lack of importance placed on TDI in the primary dentition is reflected by the failure to seek treatment even when parents/caregivers consider their child's oral health to be poor. Other authors found no association between parents/caregivers' perception of their child's oral health and seeking treatment for TDI. ${ }^{15}$ Parents are more likely to rate their child's oral health as poor if the child has anterior open bite and dental caries. ${ }^{22}$ Moreover, this aspect may be influenced by the perceptions of parents/caregivers that TDI is not a disease and that the primary dentition is temporary. ${ }^{13}$

Neither type of trauma nor number of affected teeth was a predictor for seeking treatment. A previous study reports similar results, even among parents/caregivers who were aware of the existence of TDI. ${ }^{15}$ These findings may be related to the fact that the majority of traumas were mild in both studies, regardless of the number of teeth with TDI.

None of the other sociodemographic factors analyzed were associated with the decision to seek treatment. A previous study reports that these other variables are predictors of seeking treatment when parents/caregivers are aware of the TDI. ${ }^{23}$ Moreover, studies have demonstrated that individuals who live under less privileged conditions, especially those in the age group analyzed

\section{References}

1. Feldens CA, Kramer PF, Vidal SG, Faraco Junior IM, Vítolo M. Traumatic dental injuries in the first year of life and associated factors in Brazilian infants. J Dent Child (Chic). 2008 Jan-Apr;75(1):7-13.

2. Wendt FP, Torriani DD, Assunção MCF, Romano AR, Borrow MLM, Costa CT, et al. Traumatic dental injuries in primary dentition: epidemiological study among preschool children in South Brazil. Dent Traumatol. 2010 Apr;26(2):168-173.

3. Dutra FT, Godoi PFS, Ferreira EF, Marinho AM, Borges CM, Zarzar PM. Prevalence of dental trauma and associated factors among 1-to 4-year old children. J Dent Child (Chic). 2010 Sep-Dec;77(3):146-151.

4. Bhayya DP, Shyagali TR. Traumatic injuries in the primary teeth of 4- to 6-year old school children in Gulbarga City, India. A prevalence study. Oral Health Dent Manag. 2013 Mar;12(1):17-23. herein, visit the dentist less frequently. ${ }^{12}$ In the present study, unawareness of the trauma on the part of parents/ caregivers may have exerted an influence on this aspect.

Failure to seek dental care following TDI is quite worrisome, since it reveals a lack of awareness among the population regarding the importance of the primary dentition and the possible consequences of trauma in the permanent dentition. Thus, public health services, such as the Brazilian Estratégia de Saúde da Família (Family Health Strategy), as well as public and private schools and daycare centers, could be the target of educational campaigns directed at parents/caregivers that emphasize the importance of the primary dentition, the prevention of trauma and the need for treatment following TDI to avoid the possible consequences stemming from this event. Moreover, health promotion strategies should be adopted to assist parents in recognizing oral health alterations in their children ${ }^{9}$ and to sensitize them regarding the need to seek healthcare services.

\section{Conclusions}

In the present study, the frequency of seeking treatment following TDI was low and parents/caregivers with a higher income, a poor perception of their child's oral health and a lack of awareness regarding the trauma, were more likely not to take the child to the dentist following traumatic dental injuries to primary teeth.

5. Granville-Garcia AF, Menezes VA, Lira PIC. Dental trauma and associated factors in Brazilian preschoolers. Dent Traumatol. 2006 Dec;22(6):318-22.

6. Aldrigui JM, Abanto J, Carvalho TS, Mendes FM, Wanderley MT, Bönecker M, et al. Impact of traumatic dental injuries and malocclusions on quality of life of young children. Health Qual Life Outcomes. 2011 Sep;9(9):78.

7. Yagot KH, Nazhat NY, Kuder SA. Traumatic dental injuries in nursery schoolchildren from Baghdad, Iraq. Community Dent Oral Epidemiol. 1988 Oct;16(5):292-3.

8. Lam R, Abbot P, Lloyd C, Lloyd C, Kruger E, Tennant M. Dental Trauma in an Australian rural centre. Dent Traumatol. 2008 Dec;24(6):663-70.

9. Ramos-Jorge ML, Ramos-Jorge J, Mota-Veloso I, Oliva KJ, Zarzar PM, Marques LS. Parents' recognition of dental trauma in their children. Dent Traumatol. 2013 Aug;29(4):266-71. 
10. Cardoso M, Rocha MJC. Traumatized primary teeth in children assisted at the Federal University of Santa Catarina, Brazil. Dent Traumatol. 2002 Jun;18(3):129-33.

11. Talekar BS, Rozier RG, Slade GD, Ennett ST. Parental perceptions of their preschool-aged children's oral health. J Am Dent Assoc. 2005 Mar;136(3):364-72.

12. Sohn W, Taichman LS, Ismail AI, Reisine S. Caregiver's perception of child's oral health status among low-income African Americans. Pediatr Dent. 2008 Nov-Dec;30(6):480-7.

13. Robson F, Ramos-Jorge ML, Bendo CB, Vale MP, Paiva SM, Pordeus IA. Prevalence and determining factors of traumatic injuries to primary teeth in preschool children. Dent Traumatol. 2009 Feb;25(1):118-22.

14. Camargo MBJ, Barros AJD, Frazão P, Matijasevich A, Santos IS, Peres MA, et al. Preditores da realização de consultas odontológicas de rotina e por problemas em pré-escolares. Rev Saude Publica. 2012 Feb;46(1):87-97.

15. Viegas CM, Scarpelli AC, Carvalho AC, Ferreira FM, Pordeus IA, Paiva SM. Predisposing factors for traumatic dental injuries in Brazilian preschool children. Eur J Paediatr Dent. 2010 Jun;11(2):59-65.

16. IBGE: Campina Grande - Paraíba [homepage on the internet]. Rio de Janeiro: Instituto Brasileiro de Geografia e Estatística [cited 2012 Jan 08]. Available from: http://biblioteca.ibge.gov. br/visualizacao/dtbs/paraiba/campinagrande.pdf.
17. Andreasen JO, Andreasen FM, Andersson L. Textbook and color atlas of traumatic injuries to the teeth. 4nd ed. Copenhagen: Munskgaard International Publishers; 2007. 912 p.

18. Granville-Garcia AF, Vieira I, Siqueira MJ, Menezes VA, Cavalcanti AL. Traumatic dental injuries and associated factors among Brazilian preschool children aged 1-5 years. Acta Odontol Latinoam. 2010 May;23(1):47-52.

19. Ferreira JMS, Andrade EMF, Katz CRT, Rosenblatt A. Prevalence of dental trauma in deciduous teeth of Brazilian children. Dent Traumatol. 2009 Apr;25(2):219-23.

20. Bijella MFTB, Yared FNFG, Bijella VT, Lopes ES. Occurrence of primary incisor traumatism in Brazilian children: a house-by-house survey. ASDC J Dent Child. 1990 Nov-Dec;57(6):424-7.

21. Al-Majed I, Murray JJ, Maguire A. Prevalence of dental trauma in 5-6- and 12-14-year-old boys in Ryadh, Saudi Arabia. Dent Traumatol. 2001 Aug;17(4):153-8.

22. Piovesan C, Marquezan M, Kramer PF, Bönecker M, Ardenghi TM. Socioeconomic and clinical factors associated with caregiver's perceptions of children's oral health in Brazil. Community Dent Oral Epidemiol. 2011 Jun;39(3):260-7.

23. Viegas CM, Scarpelli AC, Carvalho AC, Ferreira FM, Pordeus IA, Paiva SM. Impact of traumatic dental injury on quality of life among Brazilian preschool children and their families. Pediatr Dent. 2012 Jul-Aug;34(4):300-6. 